\title{
Dynamic Transbilayer Lipid Asymmetry
}

\author{
Gerrit van Meer \\ Bijvoet Center and Institute of Biomembranes, Utrecht University, $3584 \mathrm{CH}$ Utrecht, The Netherlands \\ Correspondence: g.vanmeer@uu.nl
}

Cells have thousands of different lipids. In the plasma membrane, and in membranes of the late secretory and endocytotic pathways, these lipids are not evenly distributed over the two leaflets of the lipid bilayer. The basis for this transmembrane lipid asymmetry lies in the fact that glycerolipids are primarily synthesized on the cytosolic and sphingolipids on the noncytosolic surface of cellular membranes, that cholesterol has a higher affinity for sphingolipids than for glycerolipids. In addition, P4-ATPases, "flippases," actively translocate the aminophospholipids phosphatidylserine and phosphatidylethanolamine to the cytosolic surface. $\mathrm{ABC}$ transporters translocate lipids in the opposite direction but they generally act as exporters rather than "floppases." The steady state asymmetry of the lipids can be disrupted within seconds by the activation of phospholipases and scramblases. The asymmetric lipid distribution has multiple implications for physiological events at the membrane surface. Moreover, the active translocation also contributes to the generation of curvature in the budding of transport vesicles.

\begin{abstract}
A lipid bilayer consisting of phosphatidylAcholine (PC) with one saturated and one unsaturated acyl chain is stable, flexible, and semipermeable. It is the simplest model of a biomembrane. In such membranes, PC with a spin label on its choline headgroup diffused rapidly in the plane of the membrane with a diffusion coefficient of $1.8 \mu \mathrm{m}^{2} / \mathrm{sec}$ (Devaux and McConnell 1972). In contrast, PC movement between leaflets, "flip-flop," was slow with a half-time of $>6 \mathrm{~h}$ at $30^{\circ} \mathrm{C}$ (Kornberg and McConnell 1971). Similar half-times for PC flip-flop were measured in erythrocyte membranes, a mammalian plasma membrane with a complex lipid composition (Rousselet et al. 1976; Renooij and Van Golde 1977; van Meer et al. 1980). Interestingly, the erythrocyte
\end{abstract}

membrane maintains an asymmetric lipid distribution across the lipid bilayer with all of its phosphatidylserine (PS) and most of its phosphatidylethanolamine (PE) in the cytosolic leaflet (Bretscher 1972; Verkleij et al. 1973). A critical discussion of these early data and the techniques used can be found in $(\mathrm{Op}$ den Kamp 1979).

It was then observed that the enrichment of aminophospholipids in the cytosolic leaflet is maintained by an ATP-consuming translocator that flips these lipids from the outer leaflet across the lipid bilayer (Seigneuret and Devaux 1984). The flippase was later identified as a P4-ATPase (Tang et al. 1996; Soupene and Kuypers 2006). Around the same time it was found that an $\mathrm{ABC}$ transporter, $\mathrm{ABCB} 4$, was

Editor: Kai Simons

Additional Perspectives on The Biology of Lipids available at www.cshperspectives.org

Copyright (C) 2011 Cold Spring Harbor Laboratory Press; all rights reserved; doi: 10.1101/cshperspect.a004671

Cite this article as Cold Spring Harb Perspect Biol 2011;3:a004671 


\section{G. van Meer}

involved in transporting PC into the bile (Smit et al. 1993), and studies on the closely related $A B C B 1$ proved that these transporters can translocate lipids across the plasma membrane onto acceptors in the extracellular space (van Helvoort et al. 1996). Finally, evidence was provided for passive, bidirectional movement of lipids across the ER membrane and under some conditions across the plasma membrane, in which cases the responsible proteins have not yet been unequivocally identified (Sanyal and Menon 2009; Bevers and Williamson 2010). Thus, we now have a general picture of how lipid asymmetry is generated, maintained, and disrupted. However, there are still important gaps in our knowledge. For example, the transbilayer orientation of the sterols that make up one-third of the lipids in eukaryotic plasma membranes has still not been resolved satisfactorily. Moreover, we do not understand mechanistically how translocators and exporters work and how their activity is regulated.

\section{TRANSBILAYER LIPID ASYMMETRY}

\section{Model Membrane Lipid Asymmetry}

Gentle hydration of mixtures of membrane lipids generally results in multilamellar liposomes with a symmetrical distribution of the various lipids across the bilayer. However, when the curvature of the membranes is increased by sonication phospholipids with a small headgroup tend to be enriched in the more highly curved inner leaflet at the cost of the more cylindrical PC (Berden et al. 1975). Asymmetric model membranes can be prepared in several ways, the simplest being the adjoining two lipid monolayers of different chemical composition into an "asymmetric black lipid membrane" (Montal and Mueller 1972). Asymmetric vesicles have been formed by inserting a specific lipid to preformed liposomes, spontaneously (van Meer and Simons 1986) or via methylbeta-cyclodextrin (Cheng et al. 2009), or by the exchange of short-chain lipids between liposome populations (Pagano et al. 1981). Alternatively, phospholipid asymmetry was induced by a transmembrane $\mathrm{pH}$ gradient (Hope et al.
1989). Asymmetric planar bilayers have also been prepared on solid supports (Kiessling et al. 2006).

Natural Membrane Lipid Asymmetry

\section{Erythrocytes}

An asymmetric distribution of phospholipids was first established for erythrocytes. Erythrocytes are a convenient experimental model for eukaryotic plasma membranes: because they lack internal membranes, their lipids exist in only two pools, that in the outer leaflet and that in the inner leaflet. Quantitative experiments are not complicated by a pool of lipids in intracellular membranes, which may contain some $85 \%$ of all cellular lipids (Griffiths et al. 1989). Initially, PE was found to be less accessible for an amino-reagent in intact erythrocytes than in opened cells (Bretscher 1972). It was then observed that most of the erythrocyte sphingomyelin (SM) and PC were accessible to exogenous phospholipases, whereas most of the PE and essentially all PS were protected (Verkleij et al. 1973). Whereas cholesterol has been shown by many biophysical approaches to have a preferential interaction with SM, indirect evidence assigned most of it to the cytosolic leaflet (see below) (Schroeder et al. 1991).

\section{Viral Membranes}

A number of membrane-enveloped viruses obtains its membranes by a budding event whereby the nucleocapsid has enveloped itself in a part of the plasma membrane. Although they contain virus specific membrane proteins, their lipid comoposition and organization may reflect that of the plasma membrane of origin. It turns out that the transbilayer distribution of the phospholipids is remarkably similar to that found in the erythrocyte membrane with most of the PS and PE inside (for a summary, see van Meer et al. 1981). These studies have taught some additional lessons. (a) Most SM was found to be accessible to exogenous phospholipase C (Tsai and Lenard 1975) or sphingomyelinase (Allan and Quinn 1989), and it was concluded that all SM resides in the 
outer leaflet. However, only $40 \%$ of the SM was calculated to be on the outside of the same Semliki Forest virus when the rate of hydrolysis was kinetically analyzed (van Meer et al. 1981), and even less in influenza virus when analyzed by a phospholipid transfer protein or phospholipase C (Rothman et al. 1976). It has been reported for liposomes that phospholipase C (Sundler et al. 1978) and sphingomyelinase (Contreras et al. 2003) can induce transbilayer translocation of inner leaflet lipids, unless the substrate lipid is only a minor fraction of the lipids in the outer leaflet. This may have been the case in the Rothman study (see under b). Thus, the orientation of SM remains to be settled. (b) From the fact that Rothman and colleagues found only $30 \%$ of the phospholipids in the virus outer leaflet, they concluded that the outer surface of influenza virus that budded from kidney cells must have been enriched in glycolipids (Rothman et al. 1976). Indeed, it was found later that influenza virus buds from the apical surface of polarized epithelial cells, and that the apical surface of such cells is enriched in glycosphingolipids (reviewed in Simons and van Meer 1988). Experimentally, the sialic acidcontaining glycolipids (gangliosides) were found exclusively on the outer viral surface (Stoffel et al. 1975; Stoffel and Sorgo 1976) in line with their presumed presence in the outer leaflet of the cellular plasma membrane.

\section{Nucleated Cells}

The studies on viral membranes suggested that the plasma membrane of nucleated cells displays an asymmetric distribution of lipids similar to that of erythrocytes, albeit less outspoken. This was confirmed by studies on isolated chromaffin granules (Buckland et al. 1978) and phagosomes (Sandra and Pagano 1978). In these membranes, which have their cytosolic surface exposed to the medium, 70\% of the PE and only a minor proportion of the SM $(<20 \%)$ was found on the cytosolic surface. Also, introducing the SM-specific equinatoxin II into the cytosol caused labeling of the Golgi, showing the presence of SM in the cytosolic leaflet, but not of the plasma membrane (Bakrac et al. 2010). The application of phospholipases and amino-reagents on intact erythroleukemic cells followed by plasma membrane isolation led to the conclusion that $80 \%-85 \%$ of SM and $10 \%-20 \%$ of PS was present in the outer leaflet of these plasma membranes, with a roughly equal distribution of $\mathrm{PC}, \mathrm{PE}$ and phosphatidylinositol (PI) (Rawyler et al. 1985). Although PI is phosphorylated by cytosolic kinases, significant fractions of various phosphoinositides have been found on the outer surface of plasma membranes (Gascard et al. 1991; Kale et al. 2010).

Independent but indirect evidence was provided by studies on the lipid organization in the apical and basolateral plasma membrane domains of epithelial cells. It was found that the tight junction that separates the two domains, acts as a barrier to lipid diffusion in the outer but not the cytosolic leaflet of the plasma membrane bilayer (Dragsten et al. 1981; van Meer and Simons 1986). As a consequence, if the free diffusion of lipid molecules in the cytosolic leaflet of the plasma membrane leads to an identical lipid composition of the cytosolic leaflets of both domains, the compositional differences between the two domains must have been because of different compositions of the outer leaflets of those domains. If the exoplasmic leaflet of the apical domain were predominantly occupied by glycosphingolipids, as is probably the case in intestinal cells (reviewed in Simons and van Meer 1988), the phospholipids of the apical domain would be mainly situated in its cytosolic leaflet. The phospholipid composition of the cytosolic leaflet of the basolateral membrane would be identical with that of the apical domain, and the distribution of the individual phospholipid classes across the basolateral membrane bilayer could be predicted from the total phospholipid composition of the basolateral membrane. For three independent studies on the apical and basolateral lipid composition (Kawai et al. 1974; van Meer and Simons 1982, 1986) the calculation for the two major phospholipid classes leads to the following numbers: $65 \%-90 \%$ of the PE and only $10 \%-25 \%$ of the PC would be localized in the cytoplasmic leaflet. 


\section{G. van Meer}

Just like the findings in erythrocytes, also in nucleated cells all (indirect) evidence points to an enrichment of cholesterol in the cytosolic leaflet of the plasma membrane (Mondal et al. 2009). This is counterintuitive because the sphingolipids in the noncytosolic leaflet should enrich the sterols there. In addition, at the typical plasma membrane content of $40 \mathrm{~mol} \%$ cholesterol (and with a cholesterol surface area half that of PC), restriction of the cholesterol to one leaflet would yield a ratio cholesterol/ phospholipid in that leaflet of 2, which is the limiting solubility of cholesterol in PC but (far) above that of PE containing membranes (Huang et al. 1999). Interestingly, sphingolipidsterol domains in one leaflet of the bilayer can apparently be recognized by glycerophospholipid-sterol domains on the opposite side (Collins 2008; Collins and Keller 2008; Wan et al. 2008; Kiessling et al. 2009). The biophysical details of the relevant interactions remain to be resolved.

\section{TRANSBILAYER LIPID TRANSLOCATION}

\section{Model Membrane Lipid Translocation}

Lipid asymmetry in model membranes is stabilized by the low tendency of the regular membrane phospholipids to flip-flop across the bilayer. However, the rate of spontaneous transmembrane translocation is very different for various lipids. Generally, lipids with a large or charged polar group, like the phospholipids and glycolipids do not move across a PC bilayer for hours, whereas lipids with a small uncharged headgroup like cholesterol, diacylglycerol (DG) or ceramide flip-flop on a (sub)second timescale (Lange et al. 1981; Bai and Pagano 1997; López-Montero et al. 2005; Krasilnikov and Yuldasheva 2009). Some charged lipids can translocate when their charge is neutralized, for example by $\mathrm{pH}$. Free fatty acids readily move across membranes at neutral $\mathrm{pH}$ (Hamilton 2003; Simard et al. 2008).

The low rate of translocation of PC across a PC membrane (Kornberg and McConnell 1971) is enhanced when defects are introduced in the membrane. Such a defect can be the boundary between liquid and solid phases at the phase transition temperature (John et al. 2002), or the presence of nonbilayer phases induced by, for example, the addition of $\mathrm{Ca}^{2+}$ to a cardiolipin-containing bilayer (Gerritsen et al. 1980) or by the generation of ceramide in membranes (Contreras et al. 2003, 2005). In addition, it has been observed that transmembrane peptides can stimulate lipid flip-flop and that this process strongly depended on the lipid composition of the liposomal bilayer (Kol et al. 2003).

\section{Natural Membrane Lipid Translocation}

\section{Erythrocytes}

The spontaneous rate of PC translocation across the erythrocyte membrane was found to be slow with a half-time of hours (Renooij et al. 1976), which was confirmed by phospholipid exchange studies (Crain and Zilversmit 1980; van Meer et al. 1980; van Meer and Op den Kamp 1982). Subsequently, Seigneuret and Devaux were able to show ATP-dependent translocation of spin-labeled PE and PS to the inner leaflet of the erythrocyte membrane (Seigneuret Devaux 1984). The responsible protein, the "flippase," was then identified as a member of the P4 subfamily of P-type transporting ATPases: ATPase II now known as ATP8A1 (Tang et al. 1996; Soupene and Kuypers 2006; Paulusma and Oude Elferink 2010). In the meantime, evidence was found to suggest that PC synthesized on the inner surface of the erythrocyte membrane by acylation of lysoPC was actively translocated outward (Andrick et al. 1991). This "floppase" activity may be because of an $\mathrm{ABC}$-transporter (Kälin et al. 2004).

Finally, it had been observed early on that blood platelets display the same lipid asymmetry across their plasma membrane as that of erythrocytes (Schick et al. 1976; Chap et al. 1977). Disruption of this asymmetry during platelet activation (Bevers et al. 1983) exposes PS, which turns out to be crucial for blood coagulation (Zwaal et al. 1977). The sudden loss of lipid asymmetry is mediated by a "scramblase." Various scramblase candidates have been proposed but none has been validated (Bevers and Williamson 2010). 


\section{Viral Membranes}

The transbilayer translocation of PC in viral membranes was found to be very slow: $7 \mathrm{~h}-\mathrm{sev}$ eral days (Rothman et al. 1976; Shaw et al. 1979; van Meer et al. 1981). There is presently no evidence that viruses actively translocate lipids.

\section{Nucleated Cells}

Aminophospholipid Flippases. The erythrocyte aminophospholipid translocator ATP8A1 (Soupene and Kuypers 2006) was originally purified from chromaffin granules (Tang et al. 1996), and 14 family members have been identified in mammals at present (Paulusma and Oude Elferink 2010). Yeast expresses five P4 ATPases (Catty et al. 1997) and they are located in the sterol- and sphingolipid rich membranes of the late secretory and endocytotic pathways (Pomorski et al. 2003). The P4-ATPases require additional subunits for their proper intracellular localization and presumably for their activity, notably the CDC50 proteins (Kato et al. 2002; Saito et al. 2004; Lenoir et al. 2009).

The P4 ATPases clear PS from the surface of blood cells: PS stimulates blood coagulation by the activation of factor $\mathrm{X}$ and the subsequent proteolytic production of thrombin (Bevers and Williamson 2010). An unexpected function is their involvement in vesicle budding. By moving lipid mass from the noncytosolic into the cytosolic leaflet they increase the lateral pressure in the cytosolic as compared to the noncytosolic leaflet, which results in curving and vesicle budding. Evidence has been provided for a role in endocytosis (Farge et al. 1999; Pomorski et al. 2003), and in vesicle transport from the Golgi (Chen et al. 1999; Hua et al. 2002; Hua and Graham 2003). As is to be expected of a physiologically relevant system, the aminophospholipid translocases are regulated by a network of kinases (Nakano et al. 2008; Roelants et al. 2010), and an asymmetry sensing system in yeast has been reported (Ikeda et al. 2008).

$A B C$ Transporters. Searching for the function of $\mathrm{ABCB} 4$, a close relative of the multidrug transporter ABCB1 (P-glycoprotein, MDR1), Smit and colleagues generated $\mathrm{Abcb} 4^{-/-}$mice and observed that these mice were unable to secrete PC into the bile (Smit et al. 1993). Subsequent studies (van Helvoort et al. 1996) showed that both $\mathrm{ABCB} 1$ and $\mathrm{ABCB} 4$ were capable of utilizing ATP to translocate a number of short-chain analogs of membrane lipids like PC, PE, SM, and the glycosphingolipid glucosylceramide (GlcCer) across the plasma membrane. It later turned out that $\mathrm{ABCB} 1$ only translocates short-chain lipids, like platelet activating factor (PAF) (Ernest and Bello-Reuss 1999; Raggers et al. 2001), whereas ABCB4 is a real PC exporter (Morita et al. 2007). Also, a number of other members of the 50 human $\mathrm{ABC}$ transporters have now been characterized as being lipid exporters (van Meer et al. 2006; Nagao et al. 2010). The most likely general working mechanism of the mammalian $\mathrm{ABC}$ transporters seems to be that they enclose hydrophobic molecules into a binding site that is open to the cytosolic leaflet. A conformational change opens this binding site to the extracellular space (or the lumen of an intracellular organelle). Molecules with a rather high water solubility will diffuse out of the binding pocket into the extracellular medium. This would be the case for many drugs (ABCB1; ABCC1) or lipids with high water solubility like PAF (ABCB1; ABCB4) and sphingosine-1phosphate (ABCC1; ABCG2) (Takabe et al. 2010). More hydrophobic molecules will not leave the binding pocket even after it opens up to the extracellular side of the membrane unless an extracellular (or lumenal) acceptor is present. This acceptor can be a lipoprotein (cholesterol, ABCA1) (Boadu et al. 2008); phospholipids (Linsel-Nitschke et al. 2005), a bile salt micelle (PC, ABCB4) (Morita et al. 2007); plant sterol (ABCG5/G8) (Levy et al. 2007), a lumenal membrane structure (PC, ABCA3; glucosylceramide, ABCA12) Mitsutake et al. 2010), or a soluble enzyme complex (very longchain fatty acyl-SCoA, ABCD1-4) (Wanders et al. 2007). It may be the case that from the binding pocket on the outside of the plasma membrane the lipid is able to move into the noncytoplasmic leaflet when an acceptor is not present. In that case, the $\mathrm{ABC}$ transporter would function as a floppase, as was found in 


\section{G. van Meer}

a study on isolated erythrocytes in the absence of any natural acceptor (Andrick et al. 1991; Kälin et al. 2004). It is very unlikely that the $\mathrm{ABC}$ transporters generally act as floppases translocating their substrates into the outer layer of the plasma membrane, after which this substrate would move out of the membrane onto the acceptor. In the latter model it is difficult to see what would be the driving force to release the substrate from the membrane, which is so nicely explained in the "exporter" or "projection" model (van Meer et al. 2006; Nagao et al. 2010).

Scramblases. In mammalian cells, one main function of the P4 ATPases is to prevent PS from appearing on the outer surface of the cell (Leventis and Grinstein 2010). Indeed, after platelet activation PS appears on the surface within seconds. In addition, PS appears on the surface of apoptotic cells where it is recognized by a PS receptor on macrophages. This is followed by ingestion of the cell corpse by the macrophage (Fadok et al. 1992). The nonspecific and bidirectional scrambling of the membrane lipids is induced by an elusive scramblase, which can be activated in various ways (Bevers and Williamson 2010). Two independent mechanisms may be involved (Schoenwaelder et al. 2009). Unexpectedly, a P4-ATPase in Caenorhabditis elegans, which should translocate PS to the cytosolic surface, appears to be required for the apoptotic appearance of PS on the cell surface (Züllig et al. 2007). Evidence has been provided that the activation of SM hydrolysis during cell signaling is because of lipid scrambling which brings outer leaflet SM to the neutral sphingomyelinase on the cytosolic surface (Tepper et al. 2000). However, the story of SM hydrolysis during signal transduction is more complex because hydrolysis can be limited to a special SM pool on a cytosolic surface (Andrieu et al. 1996), and on the other side some stimuli activate the acidic sphingomyelinase on the outside of the cell (Lin et al. 2000). Some $20 \%-30 \%$ of the SM and PC were found to be converted to ceramide and DG (Kolesnick 1989; Okazaki et al. 1989). This high concentration of ceramide might induce scrambling by its nonbilayer propensity (Contreras et al. 2003).
Other Translocators. In Farber's disease, mutations in acid ceramidase result in lysosomal storage of ceramides. Similarly, cholesterol accumulates in lysosomes in Niemann-Pick type $\mathrm{C}$ disease. It is unlikely that storage is because of the absence of a translocator in the lysosomal membrane because ceramide and cholesterol readily flip across membranes spontaneously. Indeed, it is now concluded that these lipids are present in vesicular structures in the lysosomal lumen and are unable to enter the lumenal leaflet of the lysosomal limiting membrane. Ceramide needs to be degraded to sphingosine and fatty acid. These can reach the limiting membrane spontaneously, followed by transmembrane translocation and release into the cytosol. In contrast, to enter the lysosomal membrane cholesterol needs the soluble NPC2 protein and the membrane protein NPC1 (Kolter and Sandhoff 2010). It has been argued that NPC1 is also involved in translocating sphingosine out of the lysosome (LloydEvans et al. 2008): At the low lysosomal pH, sphingosine is positively charged and does not move spontaneously across the lysosomal membrane. NPC1L1 is closely related to NPC1 and is involved in moving cholesterol across the apical membrane of intestinal cells. Probably, both proteins are needed to transport cholesterol across the glycocalyx that covers both the apical epithelial surface and the lumenal side of the lysosomal membrane.

Unlike plasma membranes, the ER membrane displays high rates of transbilayer translocation for all lipids tested (Herrmann et al. 1990; Buton et al. 1996, 2002). Evidence has been provided that distinct proteins allow passive translocation of glycerophospholipids and oligosaccharide diphosphate dolichols across the ER (Sanyal et al. 2008) and photoreceptor membranes (Menon et al. 2011). The conclusion that the yeast protein RFT1 is required for the translocation of these glycophosphodolichols (Helenius et al. 2002) was not supported by other data (Rush et al. 2009), suggesting there may be more than one mechanism. One other class of lipids that translocates across the ER membrane is the class of simple glycosphingolipids (Buton et al. 2002). The simple glycosphingolipid 
GlcCer is synthesized on the cytosolic side of the Golgi but is converted to complex glycosphingolipids in the Golgi lumen. Evidence has been presented to suggest that GlcCer is transported back to the ER to cross the membrane. Interestingly, galactosylceramide is synthesized in the ER lumen, and appeared to mix with the GlcCer pool in the cell according to their similar kinetics in various intracellular transport steps (Halter et al. 2007).

\section{Bacterial and Mitochondrial Membranes}

The cytoplasmic membrane of bacteria is a biogenic membrane like the ER. Lipids rapidly flip across it (Rothman and Kennedy 1977). This property is maintained in proteoliposomes prepared from these membranes, and not in protein-free membranes (Kubelt et al. 2002; Watkins and Menon 2002), but the responsible protein has so far escaped identification. Interestingly, two distinct but interchangeable mechanisms were identified that are required for flipping lipid-linked oligosaccharides to the outside of the cytoplasmic membrane (Alaimo et al. 2006). Surprisingly, one was a passive system and the other an $\mathrm{ABC}$ transporter. A different $\mathrm{ABC}$ transporter, MsbA, translocates nascent LPS and phospholipids to the exoplasmic surface (Doerrler et al. 2004) as was recently shown in a reconstituted system (Eckford and Sharom 2010). An independent bacterial protein translocates phospholipids and lysophospholipids (Harvat et al. 2005; Tefsen et al. 2005). As could be expected a rapid (minutes) bidirectional and energy-independent phospholipid translocation was observed across mitochondrial inner membrane (Gallet et al. 1999).

\section{PERSPECTIVES}

Even after nearly 40 years of intense research on the transbilayer organization of lipids, there are still dramatic gaps in our knowledge. It is for example unclear how cholesterol is distributed, and as argued above the methodology by which SM has been assigned to the noncytosolic leaflet is potentially flawed. Also the molecular mechanism by which the P4-ATPases and the ABC transporters move lipids across membranes is unknown, although the tremendous progress in membrane protein structure determination provides hope that such data will also explain the specificity of these systems. Lipid asymmetry and transmembrane translocation are not an isolated phenomenon, but a central aspect of the lipid economy of the cell. The process feeds into vesicle transport, protein recruitment and function, signal transduction, and physiological issues like cell death and blood clotting. The field needs input from biochemists, biophysicists, structural and cell biologists, physiologists, and clinicians: It is a great challenge to study on the one hand the molecular details of a lipid translocator and on the other hand extend this to finding a cure for hearing disorders (Stapelbroek et al. 2009). It is time to apply chemical biology and systems approaches to the unsolved questions. The field deserves it. After all, isn't it dynamic asymmetry that characterizes life?

\section{REFERENCES}

Alaimo C, Catrein I, Morf L, Marolda CL, Callewaert N, Valvano MA, Feldman MF, Aebi M. 2006. Two distinct but interchangeable mechanisms for flipping of lipid-linked oligosaccharides. Embo J 25: 967-976.

Allan D, Quinn P. 1989. Membrane phospholipid asymmetry in Semliki Forest virus grown in BHK cells. Biochim Biophys Acta 987: 199-204.

Andrick C, Broring K, Deuticke B, Haest CW. 1991. Fast translocation of phosphatidylcholine to the outer membrane leaflet after its synthesis at the inner membrane surface in human erythrocytes. Biochim Biophys Acta 1064: 235-241.

Andrieu N, Salvayre R, Levade T. 1996. Comparative study of the metabolic pools of sphingomyelin and phosphatidylcholine sensitive to tumor necrosis factor. Eur J Biochem 236: 738-745.

Bai J, Pagano RE. 1997. Measurement of spontaneous transfer and transbilayer movement of BODIPY-labeled lipids in lipid vesicles. Biochemistry 36: 8840-8848.

Bakrac B, Kladnik A, Macek P, McHaffie G, Werner A, Lakey JH, Anderluh G. 2010. A toxin-based probe reveals cytoplasmic exposure of Golgi sphingomyelin. J Biol Chem 285: 22186-22195.

Berden JA, Barker RW, Radda GK. 1975. NMR studies on phospholipid bilayers. Some factors affecting lipid distribution. Biochim Biophys Acta 375: 186-208.

Bevers EM, Williamson PL. 2010. Phospholipid scramblase: An update. FEBS Lett 584: 2724-2730.

Bevers EM, Comfurius P, Zwaal RF. 1983. Changes in membrane phospholipid distribution during platelet activation. Biochim Biophys Acta 736: 57-66. 


\section{G. van Meer}

Boadu E, Bilbey NJ, Francis GA. 2008. Cellular cholesterol substrate pools for adenosine-triphosphate cassette transporter A1-dependent high-density lipoprotein formation. Curr Opin Lipidol 19: 270-276.

Bretscher MS. 1972. Phosphatidyl-ethanolamine: Differential labelling in intact cells and cell ghosts of human erythrocytes by a membrane-impermeable reagent. Mol Biol 71: 523-528.

Buckland RM, Radda GK, Shennan CD. 1978. Accessibility of phospholipids in the chromaffin granule membrane. Biochim Biophys Acta 513: 321-337.

Buton X, Herve P, Kubelt J, Tannert A, Burger KN, Fellmann P, Muller P, Herrmann A, Seigneuret M, Devaux PF 2002. Transbilayer movement of monohexosylsphingolipids in endoplasmic reticulum and Golgi membranes. Biochemistry 41: 13106-13115.

Buton X, Morrot G, Fellmann P, Seigneuret M. 1996. Ultrafast glycerophospholipid-selective transbilayer motion mediated by a protein in the endoplasmic reticulum membrane. J Biol Chem 271: 6651-6657.

Catty P, de Kerchove d'Exaerde A, Goffeau A. 1997. The complete inventory of the yeast Saccharomyces cerevisiae P-type transport ATPases. FEBS Lett 409: 325-332.

Chap HJ, Zwaal RF, van Deenen LL. 1977. Action of highly purified phospholipases on blood platelets. Evidence for an asymmetric distribution of phospholipids in the surface membrane. Biochim Biophys Acta 467: 146-164.

Chen CY, Ingram MF, Rosal PH, Graham TR. 1999. Role for Drs2p, a P-type ATPase and potential aminophospholipid translocase, in yeast late Golgi function. J Cell Biol 147: $1223-1236$.

Cheng HT, Megha, London E. 2009. Preparation and properties of asymmetric vesicles that mimic cell membranes: Effect upon lipid raft formation and transmembrane helix orientation. J Biol Chem 284: 6079-6092.

Collins MD. 2008. Interleaflet coupling mechanisms in bilayers of lipids and cholesterol. Biophys J 94: L32-L34.

Collins MD, Keller SL. 2008. Tuning lipid mixtures to induce or suppress domain formation across leaflets of unsupported asymmetric bilayers. Proc Natl Acad Sci 105: $124-128$.

Contreras FX, Basanez G, Alonso A, Herrmann A, Goni FM. 2005. Asymmetric addition of ceramides but not dihydroceramides promotes transbilayer (flip-flop) lipid motion in membranes. Biophys J 88: 348-359.

Contreras FX, Villar AV, Alonso A, Kolesnick RN, Goni FM 2003. Sphingomyelinase activity causes transbilayer lipid translocation in model and cell membranes. J Biol Chem 278: $37169-37174$.

Crain RC, Zilversmit DB. 1980. Two nonspecific phospholipid exchange proteins from beef liver. 2. Use in studying the asymmetry and transbilayer movement of phosphatidylcholine, phosphatidylethanolamine, and sphingomyelin in intact rat erythrocytes. Biochemistry 19: $1440-1447$.

Devaux P, McConnell HM. 1972. Lateral diffusion in spinlabeled phosphatidylcholine multilayers. J Am Chem Soc 94: 4475-4481.

Doerrler WT, Gibbons HS, Raetz CR. 2004. MsbAdependent translocation of lipids across the inner membrane of Escherichia coli. J Biol Chem 279: 45102-45109.
Dragsten PR, Blumenthal R, Handler JS. 1981. Membrane asymmetry in epithelia: is the tight junction a barrier to diffusion in the plasma membrane? Nature 294: $718-722$.

Eckford PD, Sharom FJ. 2010. The reconstituted Escherichia coli MsbA protein displays lipid flippase activity. Biochem J 429: 195-203.

Ernest S, Bello-Reuss E. 1999. Secretion of platelet-activating factor is mediated by MDR1 P- glycoprotein in cultured human mesangial cells. J Am Soc Nephrol 10: 2306-2313.

Fadok VA, Voelker DR, Campbell PA, Cohen JJ, Bratton DL, Henson PM. 1992. Exposure of phosphatidylserine on the surface of apoptotic lymphocytes triggers specific recognition and removal by macrophages. J Immunol 148: 2207-2216.

Farge E, Ojcius DM, Subtil A, Dautry-Varsat A. 1999. Enhancement of endocytosis due to aminophospholipid transport across the plasma membrane of living cells. Am J Physiol 276: C725-C733.

Gallet PF, Zachowski A, Julien R, Fellmann P, Devaux PF, Maftah A. 1999. Transbilayer movement and distribution of spin-labelled phospholipids in the inner mitochondrial membrane. Biochim Biophys Acta 1418: 61-70.

Gascard P, Tran D, Sauvage M, Sulpice JC, Fukami K, Takenawa T, Claret M, Giraud F. 1991. Asymmetric distribution of phosphoinositides and phosphatidic acid in the human erythrocyte membrane. Biochim Biophys Acta 1069: $27-36$.

Gerritsen WJ, de Kruijff B, Verkleij AJ, de Gier J, van Deenen LL. 1980. $\mathrm{Ca}^{2+}$-induced isotropic motion and phosphatidylcholine flip-flop in phosphatidylcholine-cardiolipin bilayers. Biochim Biophys Acta 598: 554-560.

Griffiths G, Back R, Marsh M. 1989. A quantitative analysis of the endocytic pathway in baby hamster kidney cells. $J$ Cell Biol 109: 2703-2720.

Halter D, Neumann S, van Dijk SM, Wolthoorn J, de Maziere AM, Vieira OV, Mattjus P, Klumperman J, van Meer G, Sprong H. 2007. Pre- and post-Golgi translocation of glucosylceramide in glycosphingolipid synthesis. J Cell Biol 179: 101-115.

Hamilton JA. 2003. Fast flip-flop of cholesterol and fatty acids in membranes: implications for membrane transport proteins. Curr Opin Lipidol 14: 263-271.

Harvat EM, Zhang YM, Tran CV, Zhang Z, Frank MW, Rock CO, Saier MH Jr. 2005. Lysophospholipid flipping across the Escherichia coli inner membrane catalyzed by a transporter (LplT) belonging to the major facilitator superfamily. J Biol Chem 280: 12028-12034.

Helenius J, Ng DT, Marolda CL, Walter P, Valvano MA, Aebi M. 2002. Translocation of lipid-linked oligosaccharides across the ER membrane requires Rft1 protein. Nature 415: $447-450$.

Herrmann A, Zachowski A, Devaux PF. 1990. Proteinmediated phospholipid translocation in the endoplasmic reticulum with a low lipid specificity. Biochemistry 29: 2023-2027.

Hope MJ, Redelmeier TE, Wong KF, Rodrigueza W, Cullis PR. 1989. Phospholipid asymmetry in large unilamellar vesicles induced by transmembrane $\mathrm{pH}$ gradients. Biochemistry 28: 4181-4187. 
Hua Z, Graham TR. 2003. Requirement for neolp in retrograde transport from the Golgi complex to the endoplasmic reticulum. Mol Biol Cell 14: 4971-4983.

Hua Z, Fatheddin P, Graham TR. 2002. An essential subfamily of Drs2p-related P-type ATPases is required for protein trafficking between Golgi complex and endosomal/ vacuolar system. Mol Biol Cell 13: 3162-3177.

Huang J, Buboltz JT, Feigenson GW. 1999. Maximum solubility of cholesterol in phosphatidylcholine and phosphatidylethanolamine bilayers. Biochim Biophys Acta 1417: 89-100.

Ikeda M, Kihara A, Denpoh A, Igarashi Y. 2008. The Rim101 pathway is involved in Rsbl expression induced by altered lipid asymmetry. Mol Biol Cell 19: 1922-1931.

John K, Schreiber S, Kubelt J, Herrmann A, Muller P. 2002. Transbilayer movement of phospholipids at the main phase transition of lipid membranes: Implications for rapid flip-flop in biological membranes. Biophys $J \mathbf{8 3}$ 3315-3323.

Kale SD, Gu B, Capelluto DG, Dou D, Feldman E, Rumore A, Arredondo FD, Hanlon R, Fudal I, Rouxel T, et al 2010. External lipid PI3P mediates entry of eukaryotic pathogen effectors into plant and animal host cells. Cell 142: $284-295$.

Kälin N, Fernandes J, Hrafnsdottir S, van Meer G. 2004. Natural phosphatidylcholine is actively translocated across the plasma membrane to the surface of mammalian cells. J Biol Chem 279: 33228-33236.

Kato U, Emoto K, Fredriksson C, Nakamura H, Ohta A, Kobayashi T, Murakami-Murofushi K, Umeda M. 2002. A novel membrane protein, Ros3p, is required for phospholipid translocation across the plasma membrane in Saccharomyces cerevisiae. J Biol Chem 277: 37855-37862.

Kawai K, Fujita M, Nakao M. 1974. Lipid components of two different regions of an intestinal epithelial cell membrane of mouse. Biochim Biophys Acta 369: 222-233.

Kiessling V, Crane JM, Tamm LK. 2006. Transbilayer effects of raft-like lipid domains in asymmetric planar bilayers measured by single molecule tracking. Biophys J 91: 3313-3326.

Kiessling V, Wan C, Tamm LK. 2009. Domain coupling in asymmetric lipid bilayers. Biochim Biophys Acta 1788: 64-71.

Kol MA, van Laak AN, Rijkers DT, Killian JA, de Kroon AI, de Kruijff B. 2003. Phospholipid flop induced by transmembrane peptides in model membranes is modulated by lipid composition. Biochemistry 42: 231-237.

Kolesnick RN. 1989. Sphingomyelinase action inhibits phorbol ester-induced differentiation of human promyelocytic leukemic (HL-60) cells. J Biol Chem 264: 76177623.

Kolter T, Sandhoff K. 2010. Lysosomal degradation of membrane lipids. FEBS Lett 584: 1700-1712.

Kornberg RD, McConnell HM. 1971. Inside-outside transitions of phospholipids in vesicle membranes. Biochemistry 10: 1111-1120.

Krasilnikov OV, Yuldasheva LN. 2009. Transmembrane cholesterol migration in planar lipid membranes measured with Vibrio cholerae cytolysin as molecular tool. Biochimie 91: 620-623.
Kubelt J, Menon AK, Muller P, Herrmann A. 2002. Transbilayer movement of fluorescent phospholipid analogues in the cytoplasmic membrane of Escherichia coli. Biochemistry 41: 5605-5612.

Lange Y, Dolde J, Steck TL. 1981. The rate of transmembrane movement of cholesterol in the human erythrocyte. J Biol Chem 256: 5321-5323.

Lenoir G, Williamson P, Puts CF, Holthuis JC. 2009. Cdc50p plays a vital role in the ATPase reaction cycle of the putative aminophospholipid transporter Drs2p. J Biol Chem 284: 17956-17967.

Leventis PA, Grinstein S. 2010. The distribution and function of phosphatidylserine in cellular membranes. Annu Rev Biophys 39: 407-427.

Levy E, Spahis S, Sinnett D, Peretti N, Maupas-Schwalm F, Delvin E, Lambert M, Lavoie MA. 2007. Intestinal cholesterol transport proteins: An update and beyond. Curr Opin Lipidol 18: 310-318.

Lin T, Genestier L, Pinkoski MJ, Castro A, Nicholas S, Mogil R, Paris F, Fuks Z, Schuchman EH, Kolesnick $\mathrm{RN}$, et al. 2000. Role of acidic sphingomyelinase in Fas/CD95-mediated cell death. J Biol Chem 275: 8657-8663.

Linsel-Nitschke P, Jehle AW, Shan J, Cao G, Bacic D, Lan D, Wang N, Tall AR. 2005. Potential role of ABCA7 in cellular lipid efflux to apoA-I. J Lipid Res 46: 86-92.

Lloyd-Evans E, Morgan AJ, He X, Smith DA, Elliot-Smith E, Sillence DJ, Churchill GC, Schuchman EH, Galione A, Platt FM. 2008. Niemann-Pick disease type $\mathrm{Cl}$ is a sphingosine storage disease that causes deregulation of lysosomal calcium. Nat Med 14: 1247-1255.

López-Montero I, Rodriguez N, Cribier S, Pohl A, Velez M, Devaux PF. 2005. Rapid transbilayer movement of ceramides in phospholipid vesicles and in human erythrocytes. J Biol Chem 280: 25811-25819.

Menon I, Huber T, Sanyal S, Banerjee S, Barré P, Canis S, Warren JD, Hwa J, Sakmar TP, Menon AK. 2011. Opsin is a phospholipid flippase. Curr Biol 21: 149-153.

Mitsutake S, Suzuki C, Akiyama M, Tsuji K, Yanagi T, Shimizu H, Igarashi Y. 2010. ABCA12 dysfunction causes a disorder in glucosylceramide accumulation during keratinocyte differentiation. J Dermatol Sci 60: 128-129.

Mondal M, Mesmin B, Mukherjee S, Maxfield FR. 2009. Sterols are mainly in the cytoplasmic leaflet of the plasma membrane and the endocytic recycling compartment in CHO cells. Mol Biol Cell 20: 581-588.

Montal M, Mueller P. 1972. Formation of bimolecular membranes from lipid monolayers and a study of their electrical properties. Proc Natl Acad Sci 69: 3561-3566.

Morita SY, Kobayashi A, Takanezawa Y, Kioka N, Handa T, Arai H, Matsuo M, Ueda K. 2007. Bile salt-dependent efflux of cellular phospholipids mediated by ATP binding cassette protein B4. Hepatology 46: 188-199.

Nagao K, Kimura Y, Mastuo M, Ueda K. 2010. Lipid outward translocation by $\mathrm{ABC}$ proteins. FEBS Lett 584: 2717-2723.

Nakano K, Yamamoto T, Kishimoto T, Noji T, Tanaka K. 2008. Protein kinases Fpk1p and Fpk2p are novel regulators of phospholipid asymmetry. Mol Biol Cell 19: $1783-1797$. 


\section{G. van Meer}

Okazaki T, Bell RM, Hannun YA. 1989. Sphingomyelin turnover induced by vitamin D3 in HL-60 cells. Role in cell differentiation. J Biol Chem 264: 19076-19080.

Op den Kamp JAF. 1979. Lipid asymmetry in membranes. Annu Rev Biochem 48: 47-71.

Pagano RE, Martin OC, Schroit AJ, Struck DK. 1981. Formation of asymmetric phospholipid membranes via spontaneous transfer of fluorescent lipid analogues between vesicle populations. Biochemistry 20: 49204927.

Paulusma CC, Elferink RP. 2010. P4 ATPases-the physiological relevance of lipid flipping transporters. FEBS Lett 584: $2708-2716$.

Pomorski T, Lombardi R, Riezman H, Devaux PF, van Meer G, Holthuis JC. 2003. Drs2p-related P-type ATPases Dnflp and Dnf2p are required for phospholipid translocation across the yeast plasma membrane and serve a role in endocytosis. Mol Biol Cell 14: 1240-1254.

Raggers RJ, Vogels I, van Meer G. 2001. Multidrug-resistance P-glycoprotein (MDR1) secretes platelet-activating factor. Biochem J 357: 859-865.

Rawyler A, van der Schaft PH, Roelofsen B, Op den Kamp JA. 1985. Phospholipid localization in the plasma membrane of Friend erythroleukemic cells and mouse erythrocytes. Biochemistry 24: 1777-1783.

Renooij W, Van Golde LM. 1977. The transposition of molecular classes of phosphatidylcholine across the rat erythrocyte membrane and their exchange between the red cell membrane and plasma lipoproteins. Biochim Biophys Acta 470: 465-474.

Renooij W, Van Golde LM, Zwaal RF, Van Deenen LL. 1976. Topological asymmetry of phospholipid metabolism in rat erythrocyte membranes. Evidence for flip-flop of lecithin. Eur J Biochem 61: 53-58.

Roelants FM, Baltz AG, Trott AE, Fereres S, Thorner J. 2010 A protein kinase network regulates the function of aminophospholipid flippases. Proc Natl Acad Sci 107:34-39.

Rothman JE, Kennedy EP. 1977. Rapid transmembrane movement of newly synthesized phospholipids during membrane assembly. Proc Natl Acad Sci 74: 1821-1825.

Rothman JE, Tsai DK, Dawidowicz EA, Lenard J. 1976 Transbilayer phospholipid asymmetry and its maintenance in the membrane of influenza virus. Biochemistry 15: 2361-2370.

Rousselet A, Guthmann C, Matricon J, Bienvenue A, Devaux PF. 1976. Study of the transverse diffusion of spin labeled phospholipids in biological membranes. I. Human red bloods cells. Biochim Biophys Acta 426: 357-371.

Rush JS, Gao N, Lehrman MA, Matveev S, Waechter CJ. 2009. Suppression of Rft1 expression does not impair the transbilayer movement of Man5GlcNAc2-P-P-dolichol in sealed microsomes from yeast. J Biol Chem 284: 19835-19842.

Saito K, Fujimura-Kamada K, Furuta N, Kato U, Umeda M, Tanaka K. 2004. Cdc50p, a protein required for polarized growth, associates with the Drs2p P-Type ATPase implicated in phospholipid translocation in Saccharomyces cerevisiae. Mol Biol Cell 15: 3418-3432.
Sandra A, Pagano RE. 1978. Phospholipid asymmetry in LM cell plasma membrane derivatives: polar head group and acyl chain distributions. Biochemistry 17: 332-338.

Sanyal S, Menon AK. 2009. Flipping lipids: Why an' what's the reason for? ACS Chem Biol 4: 895-909.

Sanyal S, Frank CG, Menon AK. 2008. Distinct flippases translocate glycerophospholipids and oligosaccharide diphosphate dolichols across the endoplasmic reticulum. Biochemistry 47: 7937-7946.

Schick PK, Kurica KB, Chacko GK. 1976. Location of phosphatidylethanolamine and phosphatidylserine in the human platelet plasma membrane. J Clin Invest 57: 1221-1226.

Schoenwaelder SM, Yuan Y, Josefsson EC, White MJ, Yao Y, Mason KD, O’Reilly LA, Henley KJ, Ono A, Hsiao S, et al. 2009. Two distinct pathways regulate platelet phosphatidylserine exposure and procoagulant function. Blood 114: $663-666$.

Schroeder F, Nemecz G, Wood WG, Joiner C, Morrot G, Ayraut-Jarrier M, Devaux PF. 1991. Transmembrane distribution of sterol in the human erythrocyte. Biochim Biophys Acta 1066: 183-192.

Seigneuret M, Devaux PF. 1984. ATP-dependent asymmetric distribution of spin-labeled phospholipids in the erythrocyte membrane: relation to shape changes. Proc Natl Acad Sci 81: 3751-3755.

Shaw JM, Moore NF, Patzer EJ, Correa-Freire MC, Wagner RR, Thompsom TE. 1979. Compositional asymmetry and transmembrane movement of phosphatidylcholine in vesicular stomatitis virus membranes. Biochemistry 18: $538-543$.

Simard JR, Pillai BK, Hamilton JA. 2008. Fatty acid flip-flop in a model membrane is faster than desorption into the aqueous phase. Biochemistry 47: 9081-9089.

Simons K, van Meer G. 1988. Lipid sorting in epithelial cells. Biochemistry 27: 6197-6202.

Smit JJ, Schinkel AH, Oude Elferink RP, Groen AK, Wagenaar E, van Deemter L, Mol CA, Ottenhoff R, van der Lugt NM, van Roon MA, et al. 1993. Homozygous disruption of the murine mdr2 P-glycoprotein gene leads to a complete absence of phospholipid from bile and to liver disease. Cell 75: 451-462.

Soupene E, Kuypers FA. 2006. Identification of an erythroid ATP-dependent aminophospholipid transporter. $\mathrm{Br} \mathrm{J}$ Haematol 133: 436-438.

Stapelbroek JM, Peters TA, van Beurden DH, Curfs JH, Joosten A, Beynon AJ, van Leeuwen BM, van der Velden LM, Bull L, Oude Elferink RP, et al. 2009. ATP8B1 is essential for maintaining normal hearing. Proc Natl Acad Sci 106: 9709-9714.

Stoffel W, Sorgo W. 1976. Asymmetry of the lipid-bilayer of Sindbis virus. Chem Phys Lipids 17: 324-335.

Stoffel W, Anderson R, Stahl J. 1975. Studies on the asymmetric arrangement of membrane-lipid-enveloped virions as a model system. Hoppe-Seylers Z Physiol Chem 356: $1123-1129$.

Sundler R, Alberts AW, Vagelos PR. 1978. Phospholipases as probes for membrane sideness. Selective analysis of the outer monolayer of asymmetric bilayer vesicles. J Biol Chem 253: 5299-5304. 
Takabe K, Kim RH, Allegood JC, Mitra P, Ramachandran S, Nagahashi M, Harikumar KB, Hait NC, Milstien S, Spiegel S. 2010. Estradiol induces export of sphingosine 1-phosphate from breast cancer cells via $\mathrm{ABCC} 1$ and ABCG2. J Biol Chem 285: 10477-10486.

Tang X, Halleck MS, Schlegel RA, Williamson P. 1996. A subfamily of P-type ATPases with aminophospholipid transporting activity. Science 272: 1495-1497.

Tefsen B, Geurtsen J, Beckers F, Tommassen J, de Cock H. 2005. Lipopolysaccharide transport to the bacterial outer membrane in spheroplasts. J Biol Chem 280: 4504-4509.

Tepper AD, Ruurs P, Wiedmer T, Sims PJ, Borst J, van Blitterswijk WJ. 2000. Sphingomyelin hydrolysis to ceramide during the execution phase of apoptosis results from phospholipid scrambling and alters cell-surface morphology. J Cell Biol 150: 155-164.

Tsai KH, Lenard J. 1975. Asymmetry of influenza virus membrane bilayer demonstrated with phospholipase C. Nature 253: 554-555.

van Helvoort A, Smith AJ, Sprong H, Fritzsche I, Schinkel AH, Borst P, van Meer G. 1996. MDR1 P-glycoprotein is a lipid translocase of broad specificity, while MDR3 P-glycoprotein specifically translocates phosphatidylcholine. Cell 87: 507-517.

van Meer G, Op den Kamp JA. 1982. Transbilayer movement of various phosphatidylcholine species in intact human erythrocytes. J Cell Biochem 19: 193-204.

van Meer G, Simons K. 1982. Viruses budding from either the apical or the basolateral plasma membrane domain of MDCK cells have unique phospholipid compositions. EMBO J 1: 847-852.

van Meer G, Simons K. 1986. The function of tight junctions in maintaining differences in lipid composition between the apical and the basolateral cell surface domains of MDCK cells. EMBO J 5: 1455-1464. van Meer G, Simons K, Op den Kamp JA, van Deenen LM. 1981. Phospholipid asymmetry in Semliki Forest virus grown on baby hamster kidney (BHK-21) cells. Biochemistry 20: 1974-1981.

van Meer G, Halter D, Sprong H, Somerharju P, Egmond MR. 2006. ABC lipid transporters: Extruders, flippases, or flopless activators? FEBS Lett 580: 1171-1177.

van Meer G, Poorthuis BJ, Wirtz KW, Op den Kamp JA, van Deenen LL. 1980. Transbilayer distribution and mobility of phosphatidylcholine in intact erythrocyte membranes. A study with phosphatidylcholine exchange protein. Eur J Biochem 103: 283-288.

Verkleij AJ, Zwaal RFA, Roelofsen B, Comfurius P, Kastelijn D, van Deenen LLM. 1973. The asymmetric distribution of phospholipids in the human red cell membrane. A combined study using phospholipases and freezeetch electron microscopy. Biochim Biophys Acta 323: $178-193$.

Wan C, Kiessling V, Tamm LK. 2008. Coupling of cholesterol-rich lipid phases in asymmetric bilayers. Biochemistry 47: 2190-2198.

Wanders RJ, Visser WF, van Roermund CW, Kemp S, Waterham HR. 2007. The peroxisomal ABC transporter family. Pflugers Arch 453: 719-734.

Watkins WE, Menon AK. 2002. Reconstitution of phospholipid flippase activity from E. coli inner membrane: A test of the protein translocon as a candidate flippase. Biol Chem 383: 1435-1440.

Züllig S, Neukomm LJ, Jovanovic M, Charette SJ, Lyssenko NN, Halleck MS, Reutelingsperger CP, Schlegel RA, Hengartner MO. 2007. Aminophospholipid translocase TAT-1 promotes phosphatidylserine exposure during C. elegans apoptosis. Curr Biol 17: 994-999.

Zwaal RF, Comfurius P, van Deenen LL. 1977. Membrane asymmetry and blood coagulation. Nature 268: 358-360. 




\section{Dynamic Transbilayer Lipid Asymmetry}

Gerrit van Meer

Cold Spring Harb Perspect Biol 2011; doi: 10.1101/cshperspect.a004671 originally published online March 23, 2011

Subject Collection The Biology of Lipids

Role of Lipids in Virus Replication Maier Lorizate and Hans-Georg Kräusslich

Model Answers to Lipid Membrane Questions Ole G. Mouritsen

\section{Glycosphingolipid Functions} Clifford A. Lingwood

Regulation of Cholesterol and Fatty Acid Synthesis

Jin Ye and Russell A. DeBose-Boyd

Lipid-Mediated Endocytosis

Helge Ewers and Ari Helenius

\section{Fluorescence Techniques to Study Lipid}

Dynamics

Erdinc Sezgin and Petra Schwille

Lysosomal Lipid Storage Diseases

Heike Schulze and Konrad Sandhoff

\section{Distribution and Functions of Sterols and} Sphingolipids

J. Thomas Hannich, Kyohei Umebayashi and Howard Riezman
Membrane Organization and Lipid Rafts Kai Simons and Julio L. Sampaio

Shotgun Lipidomics on High Resolution Mass

Spectrometers

Dominik Schwudke, Kai Schuhmann, Ronny

Herzog, et al.

Glycosphingolipid Functions Clifford A. Lingwood

Phosphoinositides in Cell Architecture Annette Shewan, Dennis J. Eastburn and Keith Mostov

Synthesis and Biosynthetic Trafficking of Membrane Lipids

Tomas Blom, Pentti Somerharju and Elina Ikonen

Lipid Polymorphisms and Membrane Shape Vadim A. Frolov, Anna V. Shnyrova and Joshua Zimmerberg

Specificity of Intramembrane Protein-Lipid Interactions

Francesc-Xabier Contreras, Andreas Max Ernst, Felix Wieland, et al.

Dynamic Transbilayer Lipid Asymmetry Gerrit van Meer

For additional articles in this collection, see http://cshperspectives.cshlp.org/cgi/collection/

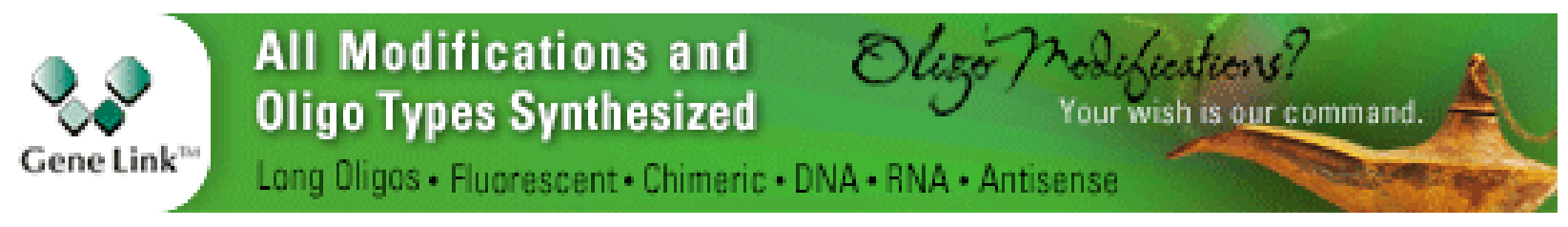

Copyright @ 2011 Cold Spring Harbor Laboratory Press; all rights reserved 